Research Article

\title{
Experimental Study on the Deformation and Strength Characteristics of Saturated Clay under Cyclic Loading
}

\author{
Jian Zhang $\mathbb{D}^{1},{ }^{1}$ Yangguang Sun, ${ }^{2}$ and Jiuting $\mathrm{Cao}^{3}$ \\ ${ }^{1}$ Nanjing Vocational Institute of Transport Technology, Nanjing 211188, China \\ ${ }^{2}$ Guangdong Province Communications Planning and Design Institute Co., Ltd., Guangzhou 510507, China \\ ${ }^{3}$ Jiangsu Zhongshe Group Co., Ltd., Wuxi 214072, China
}

Correspondence should be addressed to Jian Zhang; 18626439990@163.com

Received 23 July 2019; Revised 3 January 2020; Accepted 10 January 2020; Published 29 January 2020

Academic Editor: Flavio Stochino

Copyright (C) 2020 Jian Zhang et al. This is an open access article distributed under the Creative Commons Attribution License, which permits unrestricted use, distribution, and reproduction in any medium, provided the original work is properly cited.

The deformation and strength characteristics of saturated clay are studied through a cyclic triaxial test of clay in the Wenchuan earthquake area. Specifically, the effects of cyclic stress ratio, initial shear stress, and vibration frequency on the dynamic characteristics of saturated clay are analysed. Results show a failure strain in the dynamic strain development of saturated clay. Before the failure strain, the dynamic strain of soil develops slowly. After the failure strain, the soil strain increases sharply and leads to failure. Under the same confining pressure, the failure strain produced by different cyclic stress ratios has a linear relationship with the failure frequency. The dynamic strain development curve of saturated clay can be simplified to failure, transition, and stability types, which are mainly affected by the cyclic stress ratio. Initial shear stress and vibration frequency have significant effects on the deformation and strength characteristics of saturated clay. The larger the initial shear stress or the lower the vibration frequency is, the more sufficient the dynamic strain of soil develops and the fewer the number of cycles required to reach the same dynamic strain. Under the same number of cycles, the larger the initial shear stress or the lower the vibration frequency, the smaller the dynamic stress required to cause soil failure and the lower the dynamic strength of the soil. A turning point exists in the dynamic strength curve of clay. The smaller the initial shear stress or the higher the vibration frequency, the smoother the curve after the turning point and the smaller the tangent slope.

\section{Introduction}

Deep soft clay layers are widely distributed in coastal areas and inland cities of China. Many high-rise buildings, expressways, high-speed railways, and wharves have been built in these areas in recent years. Initial shear stress inevitably exists on these clay foundations. Under cyclic loading, clay exhibits different dynamic characteristics, and its deformation and strength have become the focus of research [1-3]. To ensure the safety and stability of buildings in these areas, the dynamic strain and strength of saturated clay under cyclic loading must be examined.

The cyclic compression tests of reconstructed clay by Lee [4] and Yasuhara et al. [5] showed that the dynamic strength curves of soil vary with different failure criteria. The failure of soft clay under cyclic loading is often sudden and has the characteristic of brittle failure. Failure of the soil structure will cause serious deformation, which may lead to serious engineering accidents. Therefore, the strength and deformation characteristics of saturated soft clay under cyclic loading must be analysed. An appropriate criterion for strain failure should be determined.

Hyodo et al. [6] found through cyclic triaxial tests that the elastic strain of saturated clay has insignificant relationship with the dynamic stress amplitude, but a corresponding relationship exists with the effective stress ratio. By using similar tests, Muhanna [7] analysed the law of the vertical cumulative plastic deformation of soil under cyclic loading. Larew and Leonards [8] and Sangrey et al. [9] confirmed that saturated clay has a maximum cyclic stress ratio that does not lead to soil damage. Matsui et al. [10] conducted a cyclic shear test on Senri clay. The results 
showed that the dynamic pore water pressure in the soil increases with the increase in the number of cyclic vibrations and that high dynamic pore water pressure and strain are produced at a low loading frequency under a certain number of cyclic vibrations. When considering the influence of vibration frequency on the dynamic strain of clay, Ansal and Erken [11] argued that with a certain number of vibrations, the lower the vibration frequency, the larger the dynamic strain of soil. However, the effect of frequency on dynamic strain gradually weakens with the increase in vibration frequency. Brewer's studies showed that the dynamic pore pressure and deformation caused by low-frequency loads are larger than those generated by high-frequency loads in a vibration frequency range of $f=0.01-4 \mathrm{~Hz}$ and the same number of cyclic vibrations [12]. Moses et al. [13] drew similar conclusions by investigating cemented marine clay. Lashine [14] experimentally proved that the influence of vibration frequency on periodic strain and pore pressure can be neglected at a certain stress level. Brown et al. [15] indicated a negligible influence of the vibration frequency of cyclic load on the dynamic characteristics of saturated clay. The cyclic triaxial test results of Ariake clay by Yasuhara et al. [5] indicated that in a vibration frequency range of $f=0.1-1 \mathrm{~Hz}$, vibration frequency has a certain influence on the generation and development of pore pressure, but the higher the vibration frequency, the higher the dynamic pore pressure. Parr [16] analysed the relationship between the cumulative plastic strain rate and the number of cycles through cyclic triaxial tests and proposed a residual strain model. Monismith et al. [17] performed an experimental study on the permanent deformation of saturated clay under cyclic loading. The results indicated that the permanent deformation of soil subjected to low stress level and then high stress level is smaller than that of soil directly subjected to a high stress level. Yasuhara [18] considered that under cyclic loading, the pore water pressure in the normal consolidated clay gradually increases with the increase in the number of vibrations, thereby decreasing the effective stress and dynamic strength of the soil. Ishibashi et al. [19] proved that the existence of initial shear stress increases the total strength of soil. Goulois et al. [20] believed that the shear strength of soil decreases gradually with the increase in initial shear stress. Lefebvre and Pfendler [21] proved that the shear strength of soil decreased with the increase of initial shear stress through experiments. Moses and Rao [22] investigated the response of marine clay to cyclic torsional loading and proposed that with increase in the cyclic stress ratio, the number of cycles to reach the threshold limit also increases. The critical cyclic stress ratio level depends both on the stress level and the frequency of loading. Li et al. [23] indicated that the loading frequency has a distinct influence on the undrained cyclic behavior of natural clays. For a given number of cycles, larger shear strains and pore pressures are generated at lower frequency. Wang et al. [24] experimentally confirmed that the cyclic strength of soft clay degrades fairly rapidly with the number of cycles when there is no initial shear stress. However, the cyclic strength degrades lesser when there is an initial shear stress. Sun et al. [25] investigated the deformation behavior of natural $K_{0^{-}}$ consolidated soft clay in partially drained conditions. The results demonstrated that not only the deviator part of the stress rules accumulation but also the volumetric part significantly contributes.

The above analyses suggest that the influence of initial shear stress and vibration frequency on the dynamic characteristics of saturated clay has not reached a consistent conclusion. Therefore, through a cyclic triaxial test of saturated clay in the Wenchuan earthquake area, the present work discusses the criterion for the strain failure of saturated clay under cyclic loading. Furthermore, the influence of the cyclic stress ratio, initial shear stress, and vibration frequency on the dynamic characteristics of saturated clay are analysed to ensure the safety and stability of clay foundation under cyclic loading.

\section{Soil Samples and Plans}

2.1. Soil Samples. The clay used in this experiment was obtained from the Wenchuan earthquake area of Sichuan Province. The sampling depth was approximately 4-6 m. Table 1 lists the basic physical properties of the clay. Figure 1 displays the grain size distribution curve of the clay. According to the USCS classification method, the clay is classified as CL.

2.2. Test Procedures and Methods. A dynamic triaxial testing system (DDS-70) and remoulded soil sample with a diameter of $39.1 \mathrm{~mm}$ and height of $80 \mathrm{~mm}$ were used in this test. Figure 2 shows the photo of the dynamic triaxial testing system. Figures 3 and 4 show the compaction and saturation of specimens, respectively. The reconstituted specimens were prepared through a multilayer wet mortar method, and vacuum pumping and reversing pressure were applied to saturate the sample. The vacuum degree in the saturated cylinder was controlled to 1 atmosphere, and the vacuuming time was controlled to 2 hours. The saturation test was to observe the pore water pressure increment $\Delta u$, by applying a small confining pressure increment $\Delta \sigma_{c}$ to the sample. When pore water pressure coefficient $B$ was not less than 0.97 , the sample could be deemed to be saturated. The samples were consolidated by drainage under different confining pressures. For isotropic consolidation, after the sample was saturated, the consolidation confining pressure $\sigma_{\mathrm{c}}$ was slowly applied to the sample until the specified test confining pressure was reached. The drain valve was opened to make the sample drained and consolidated under the confining pressure, and the axial displacement and water discharge of the sample were recorded. When the pore water pressure dissipated, the vertical displacement basically did not change, and the water discharge in unit time met the specified range, then it could be considered that the isobaric consolidation was completed, and finally the drain valve was closed. Then, anisotropic consolidation was conducted after completing the isobaric consolidation. In this process, deviatoric stress is applied at the rate of $1 \mathrm{kPa} / \mathrm{min}$, and the drain valve should be opened. When the pore water pressure dissipated, the vertical displacement basically did not 
TABLE 1: Basic physical properties of clay.

\begin{tabular}{lccccccc}
\hline $\begin{array}{l}\text { Density } \rho \\
\left(\mathrm{g} / \mathrm{cm}^{3}\right)\end{array}$ & $\begin{array}{c}\text { Natural moisture } \\
\text { content } w(\%)\end{array}$ & $\begin{array}{c}\text { Specific gravity } \\
\mathrm{Gs}\end{array}$ & $\begin{array}{c}\text { Liquid limit } \\
w_{\mathrm{L}}(\%)\end{array}$ & $\begin{array}{c}\text { Plastic limit } \\
w_{\mathrm{P}}(\%)\end{array}$ & $\begin{array}{c}\text { Plasticity } \\
\text { index } I_{\mathrm{p}}\end{array}$ & $\begin{array}{c}\text { Cohesion } c \\
(\mathrm{kPa})\end{array}$ & $\begin{array}{c}\text { Internal friction } \\
\text { angle } \varphi\left({ }^{\circ}\right)\end{array}$ \\
\hline 1.78 & 21.59 & 2.72 & 37.62 & 20.26 & 17.36 & 27.15 & 16.86 \\
\hline
\end{tabular}

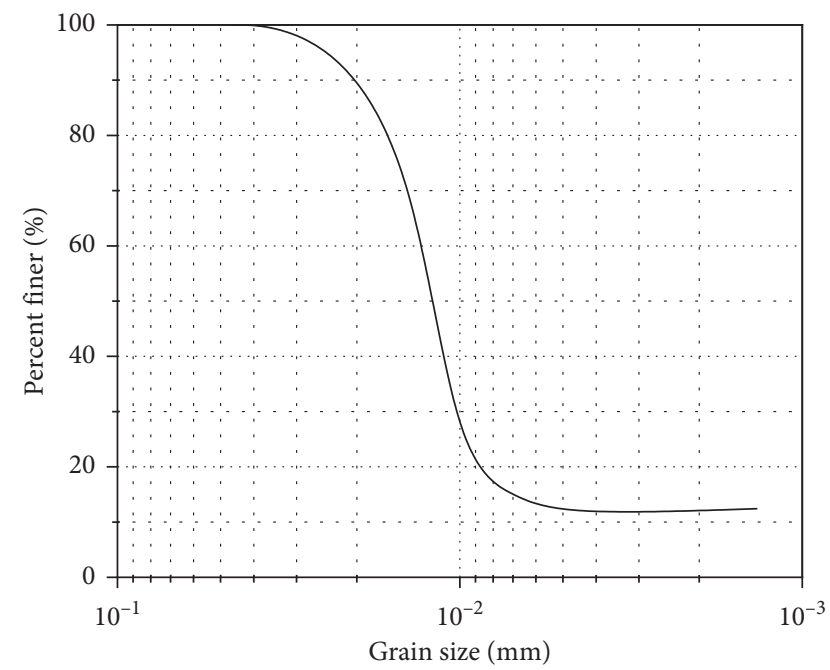

Figure 1: Grain size distribution of the clay.

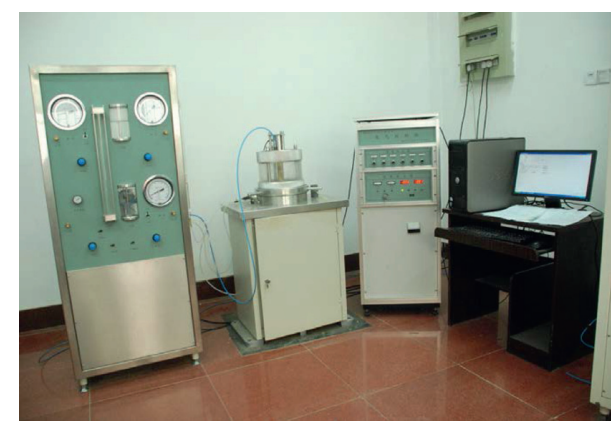

FIgURE 2: DDS-70 dynamic triaxial testing system.

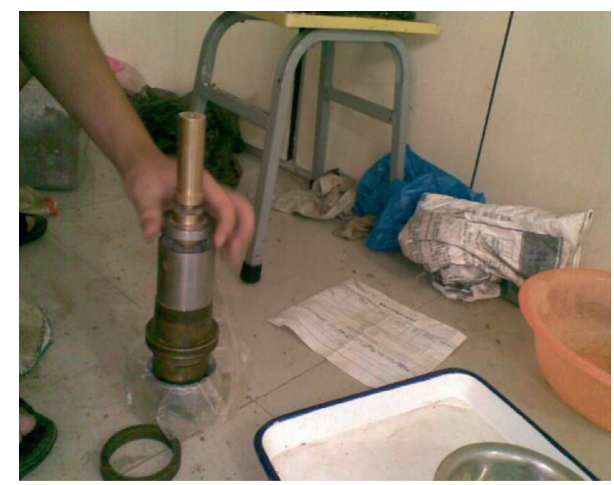

Figure 3: Sample compaction.

change, and the water discharge per unit time met the specified range, then it could be considered that the anisotropic consolidation is completed, and finally the drain valve was closed.

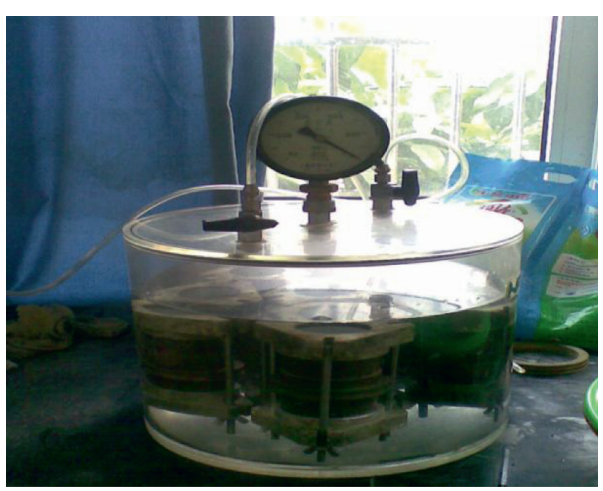

Figure 4: Sample saturation.

2.3. Test Plans. On the basis of the soil depth and research requirements, the consolidation confining pressures are $\sigma_{\mathrm{c}}=50,100$, and $150 \mathrm{kPa}$; the vibration frequencies are $f=1$, 2 , and $4 \mathrm{~Hz}$; and the cyclic stress ratios are $r=0.165,0.25$, and 0.335 . In this study, the ratio of dynamic stress amplitude $\sigma_{\mathrm{d}}$ to two times confining pressure $\sigma_{\mathrm{c}}$ is defined as the cyclic stress ratio $r$, that is,

$$
r=\frac{\sigma_{\mathrm{d}}}{2 \sigma_{\mathrm{c}}}
$$

To consider the influence of initial shear stress on the dynamic characteristics of saturated clay, cyclic triaxial tests with consolidation ratios of $K_{\mathrm{c}}=1,1.25$, and 1.5 were conducted:

$$
K_{\mathrm{c}}=\frac{\left(\sigma_{\mathrm{s}}+\sigma_{\mathrm{c}}\right)}{\sigma_{\mathrm{c}}}
$$

where $\sigma_{\mathrm{s}}$ represents the initial shear stress, $\sigma_{\mathrm{c}}$ represents the consolidation confining pressure, and the size of $K_{\mathrm{c}}$ reflects the initial shear stress level of the soil.

Table 2 presents the test scheme.

\section{Results and Analysis}

3.1. Law of Dynamic Strain Development in Saturated Clay. Figure 5 shows the dynamic strain development curve of saturated clay. The dynamic strain of saturated clay changes slightly in the initial stage of development. With the increase in the number of cycles $(N)$, the soil strain develops rapidly and damages occur under few vibrations when the strain develops to a certain value. Therefore, an evident turning point exists in the dynamic strain development curve of saturated clay. Before the turning point, the strain accumulation rate is low and the strain accumulation is small. After the turning point, the strain accumulates rapidly and the specimen is destroyed quickly. 
TABLe 2: Cyclic triaxial test scheme for saturated clay.

\begin{tabular}{lcccc}
\hline Test types & Consolidation ratio $K_{\mathfrak{c}}$ & Confining pressure $\sigma_{\mathfrak{c}}(\mathrm{kPa})$ & Vibration frequency $f(\mathrm{~Hz})$ & Cyclic stress ratio $r$ \\
\hline \multirow{3}{*}{ Isotropic consolidation } & 1 & 50 & 1 & 0.165 \\
& & 100 & 2 & 4 \\
& & 150 & 0.25 & 0.335 \\
Anisotropic consolidation & 1.25 & 50 & 4 & 0.165 \\
& 1.5 & 100 & 0.25 & 0.335 \\
\hline
\end{tabular}

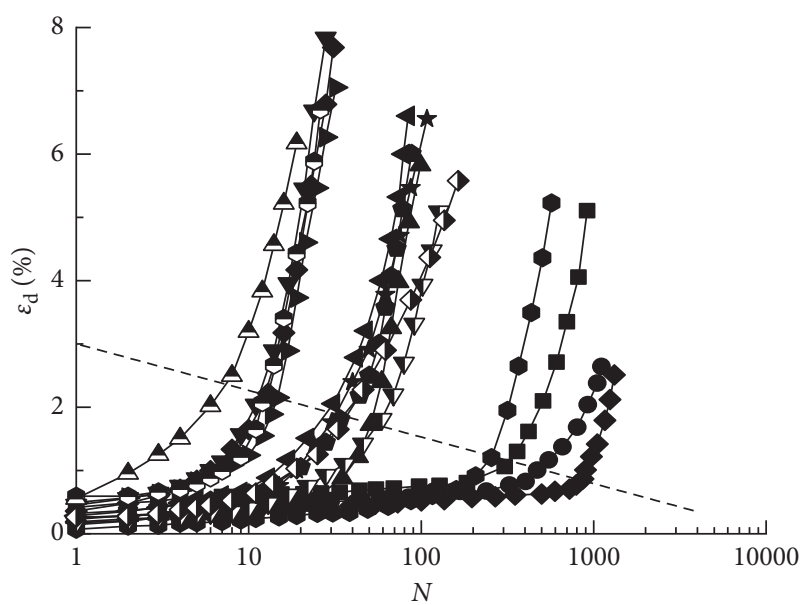

Figure 5: Relationship curves between $\varepsilon_{\mathrm{d}}$ and $N$ under different confining pressures.

The failure of the clay structure under cyclic loading is progressive. Weak cemented surfaces or bands are observed in the clay. Under cyclic loading, the weak areas are destroyed first. In this process, soil deformation is small. With the continuous action of cyclic loading, cracks gradually expand and eventually lead to serious damage of the clay structure, resulting in serious soil deformation. The appearance of the turning point on the strain curve indicates that the soil structure is about to collapse. Therefore, considering the strain value at the turning point to be the criterion of soil failure is a suitable approach.

In this study, the strain value at the turning point in the dynamic strain development of saturated clay is defined as the failure strain $\varepsilon_{\text {tp }}$. As shown in Figure 5, when the confining pressure is constant, the failure strain of the clay structure is not fixed, but varies with the cyclic stress ratio. The larger the cyclic stress ratio is, the earlier the turning point appears and the larger the corresponding strain value is. If the number of cycles corresponding to the failure strain is defined as the failure number of cycles $N_{f}$, then equation (3) can be used to fit $\varepsilon_{\text {tp }}$ and $N_{f}$.

$$
\varepsilon_{\text {tp }}=A \times \lg N_{f}+B,
$$

where $A$ and $B$ are the fitting parameters. Table 3 presents the parameters under different confining pressures.

Analysis of Figure 5 reveals that the dynamic strain development curves of saturated clay under cyclic loading can be simplified into three types, namely, failure, transition, and stability, as shown in Figure 6.
TABle 3: Parameters under different confining pressures.

\begin{tabular}{lcccc}
\hline \multicolumn{2}{l}{ Confining pressure $(\mathrm{kPa})$} & 50 & 100 & 150 \\
\hline \multirow{2}{*}{ Fitting parameters } & A & -0.383 & -0.483 & -0.489 \\
& B & 2.2801 & 2.757 & 2.762 \\
\hline
\end{tabular}

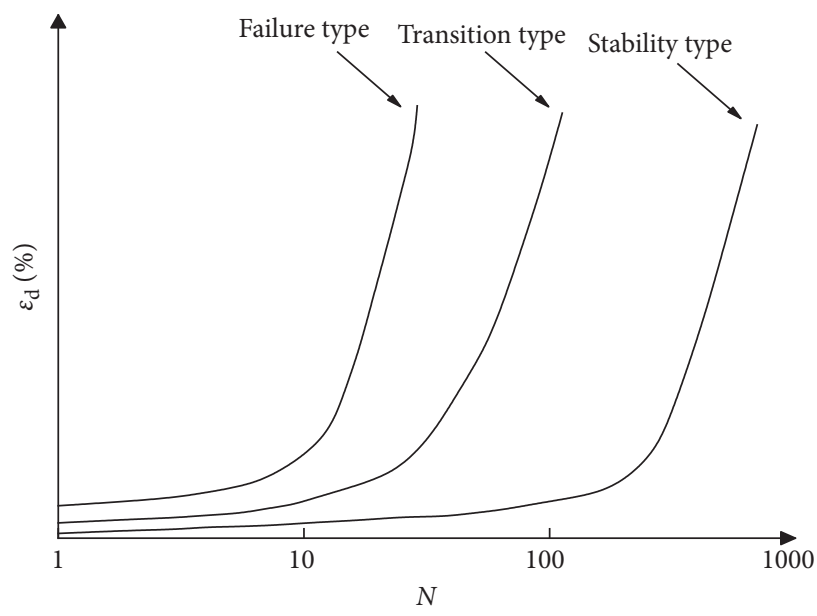

FIgURE 6: Three types of simplified curves between $\varepsilon_{\mathrm{d}}$ and $N$.

Figure 6 illustrates that when the dynamic strain development curve of saturated clay is a failure type, the dynamic strain develops rapidly with the increase in the number of cycles. With a small number of cycles, the dynamic strain amplitude of soil is large, and the soil deforms and is destroyed. When the dynamic strain development curve of saturated clay is a transition type, the dynamic strain of soil is small at the initial stage of cyclic vibration. When the number of cycles increases to a certain value, the dynamic strain fully develops to deformation and failure. When the dynamic strain development curve of saturated clay is stable, a small recoverable elastic deformation is present in the initial stage of cyclic vibration. With the continuous increase in the number of cycles, the dynamic strain amplitude becomes stable and unchanged, and the dynamic strain begins to accumulate after reaching a high number of cycles.

3.2. Influence of Cyclic Stress Ratio on the Dynamic Strain Development of Saturated Clay. Figure 7 shows the dynamic strain-number of cycle curves of saturated clay under different confining pressures and cyclic stress ratios. The dynamic strain development of saturated clay is significantly 


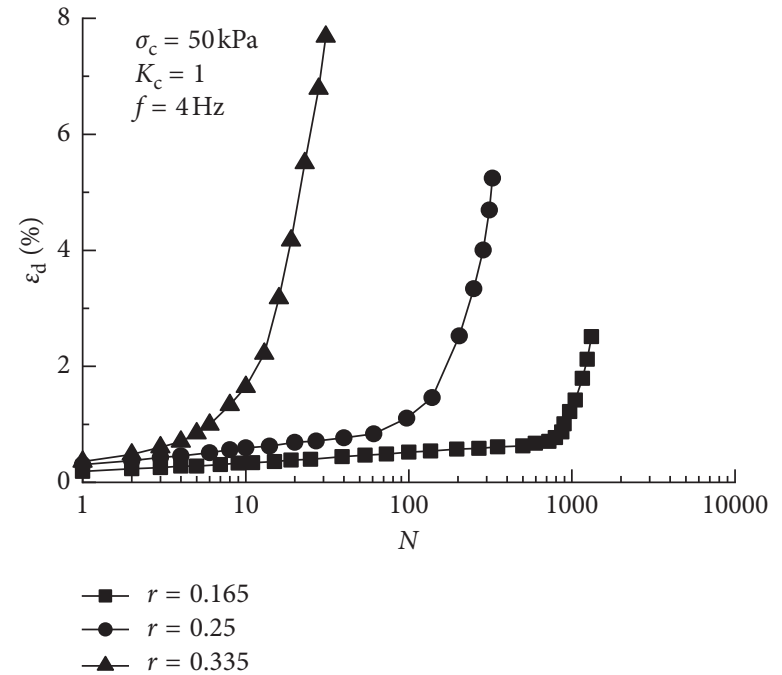

(a)

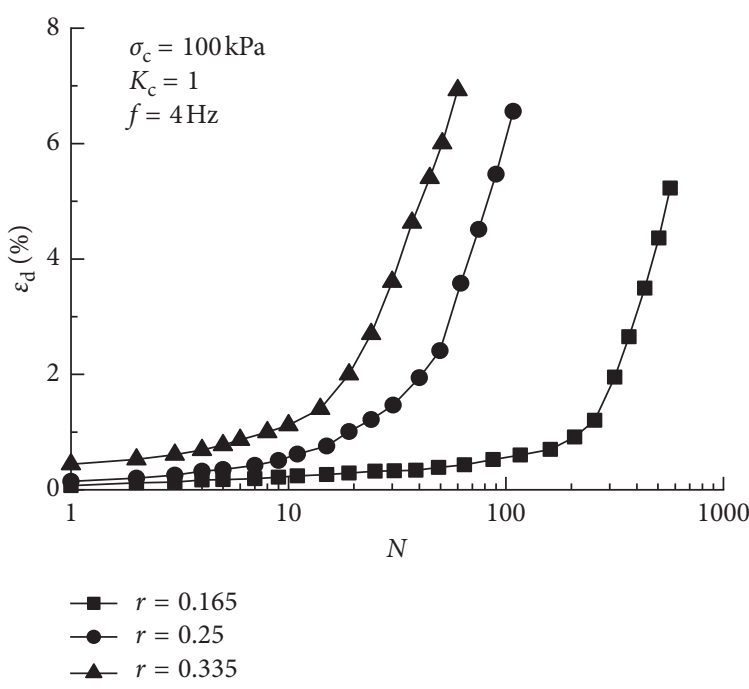

(b)

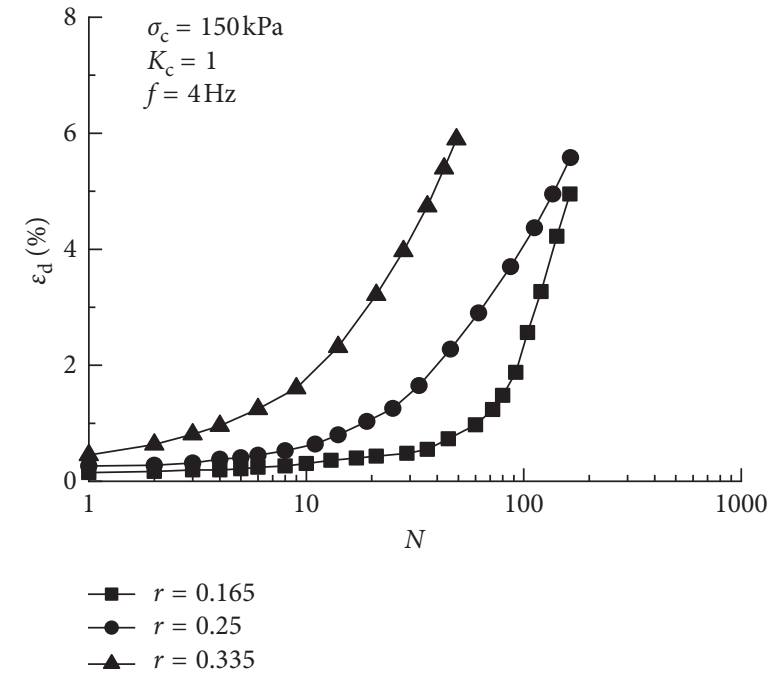

(c)

Figure 7: Relationship curves between $\varepsilon_{\mathrm{d}}$ and $N$ under different cyclic stress ratios: (a) $\sigma_{\mathrm{c}}=50 \mathrm{kPa}$, (b) $\sigma_{\mathrm{c}}=100 \mathrm{kPa}$, and (c) $\sigma_{\mathrm{c}}=150 \mathrm{kPa}$.

affected by the cyclic stress ratio under the same confining pressure, initial shear stress level, and vibration frequency. The larger the cyclic stress ratio is, the more fully the strain of clay develops and the fewer the failure number of cycles is. The lower the cyclic stress ratio, the slower the dynamic strain development of clay. With the increase in the number of cycles, the dynamic strain amplitude of soil changes slightly, and the dynamic strain begins to accumulate after reaching a high number of cycles, indicating that a critical cyclic stress ratio $r$ l exists. When the cyclic stress ratio is less than the critical cyclic stress ratio, a small recoverable elastic deformation is present in the initial stage of cyclic vibration, and the dynamic strain of soil develops slowly. The dynamic strain does not begin to accumulate until a high number of vibrations have been achieved. When the cyclic stress ratio is larger than the critical dynamic stress, the dynamic strain of soil develops sufficiently and accumulates rapidly with the increase in the number of cycles until deformation and failure occur.

The comparison of Figures 6 and 7 reveals that under the same cyclic stress ratio $r=0.165$, the cumulative strain of soil changes due to the change in confining pressure, and the dynamic strain development curve of clay changes from the stability type to the transition type. Thus, the critical cyclic stress ratio is affected by confining pressure; the larger the confining pressure, the smaller the critical cyclic stress ratio.

3.3. Influence of Initial Shear Stress on the Dynamic Strain Development of Saturated Clay. Figure 8 shows the relationship curves of dynamic strain-number of cycles of saturated clay under different confining pressures and consolidation ratios. The initial shear stress has a significant influence on the dynamic strain development of 


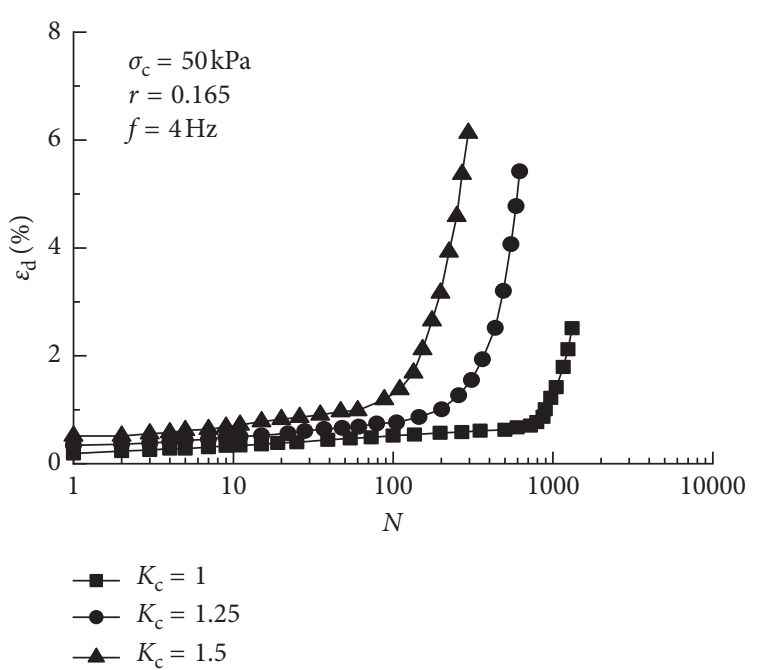

(a)

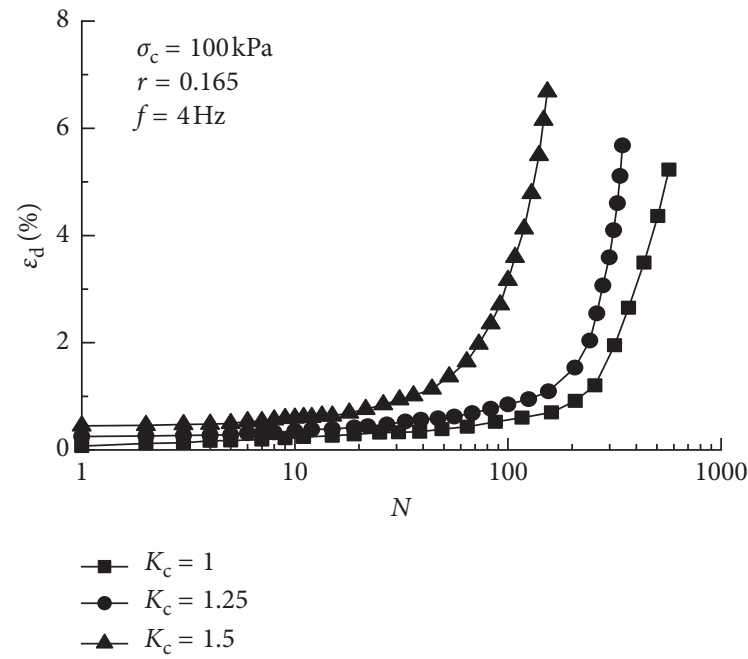

(c)

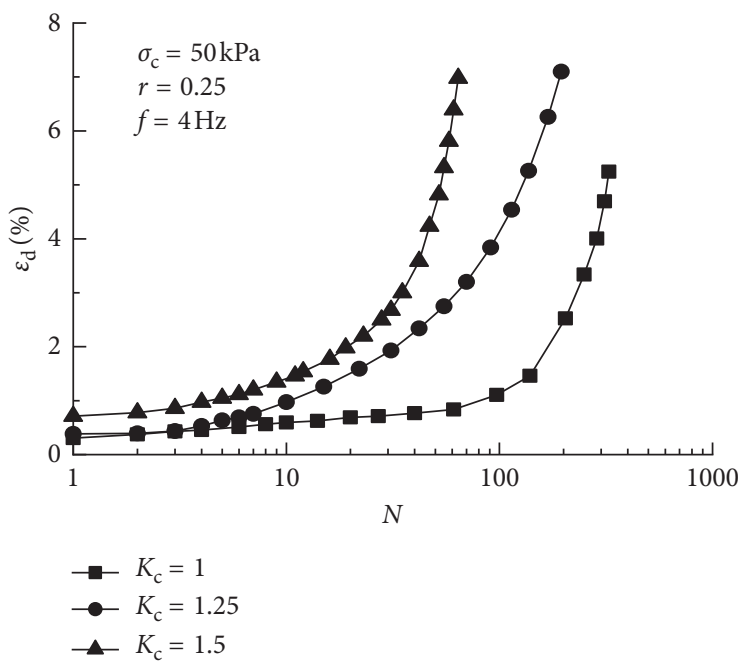

(b)

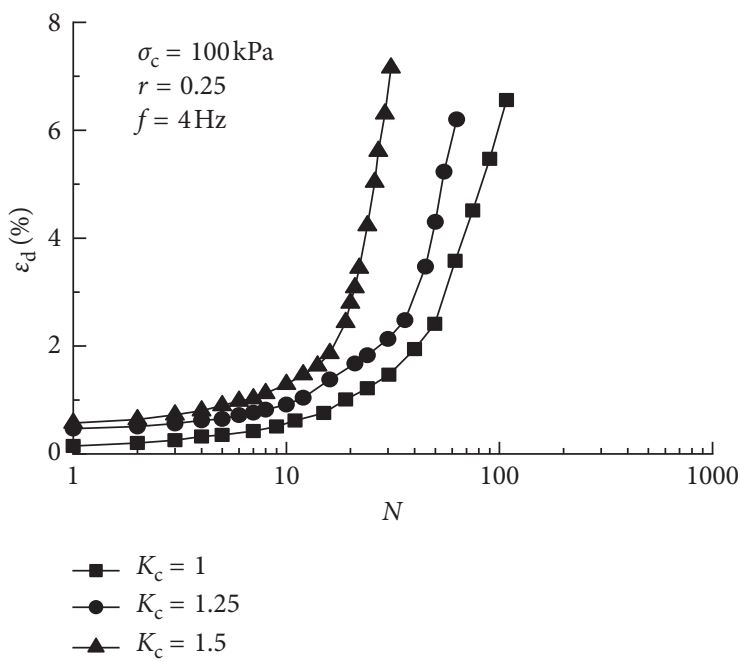

(d)

FiguRE 8: Relationship curves between $\varepsilon_{\mathrm{d}}$ and $N$ under different consolidation ratios. (a) $\sigma_{\mathrm{c}}=50 \mathrm{kPa}, r=0.165$. (b) $\sigma_{\mathrm{c}}=50 \mathrm{kPa}, r=0.25$. (c) $\sigma_{\mathrm{c}}=100 \mathrm{kPa}, r=0.165$. (d) $\sigma_{\mathrm{c}}=100 \mathrm{kPa}, r=0.25$.

saturated clay under cyclic loading. The larger the initial shear stress, the more sufficient the dynamic strain development of soil and the fewer the number of vibrations required to achieve the same dynamic strain. When the cyclic stress ratio $r=0.165$ and consolidation ratio $K_{\mathrm{c}}=1$, the dynamic strain development curve of saturated clay is stable, and the dynamic strain changes slightly with the increase in the number of cycles. At this time, the critical cyclic stress ratio should be higher than 0.165 . When the consolidation ratio increases to $K_{\mathrm{c}}=1.5$, the dynamic strain development curve of saturated clay is a transition type, and the dynamic strain develops slowly in the initial stage. When the number of vibration increases and the number of cycles reaches an increased level, the dynamic strain develops rapidly until deformation failure occurs, and the critical cyclic stress ratio should be close to 0.165 . Therefore, initial shear stress has a significant influence on the critical cyclic stress ratio of saturated clay, indicating that the larger the initial shear stress, the smaller the critical cyclic stress ratio of soil.

3.4. Influence of Vibration Frequency on the Dynamic Strain Development of Saturated Clay. Many local and international experimental studies have been conducted on the influence of vibration frequency on saturated clay, but their conclusions differ. Thus, continuing the experimental study is necessary. Figure 9 depicts the dynamic strain-number of cycle curves of saturated clay under different confining pressures and vibration frequencies. The strain development of saturated clay is affected by the vibration frequency in the range of $1-4 \mathrm{~Hz}$, indicating that the lower the vibration frequency is, the more sufficient the strain development is, the easier the deformation accumulates, and the fewer the number of vibrations required for the specimen to reach the failure criteria. The main reason for this law is that the lower 


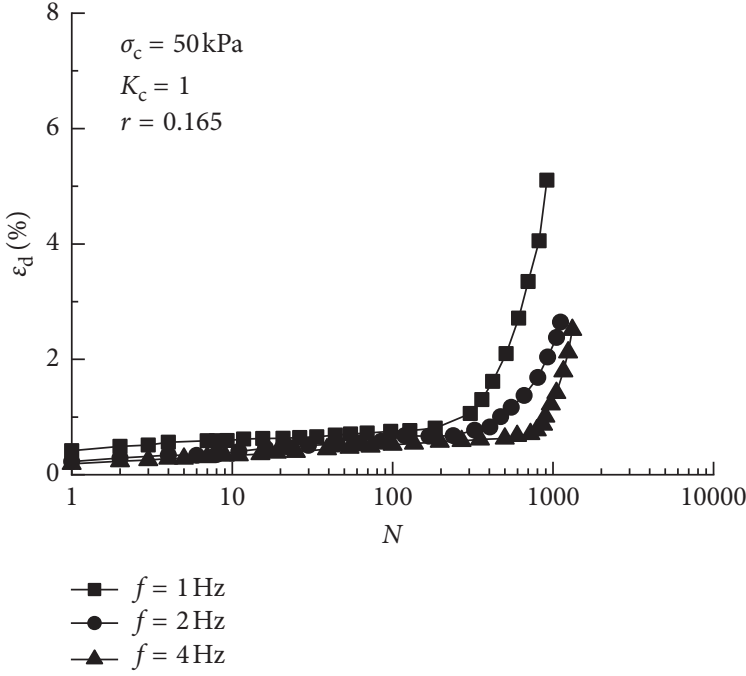

(a)

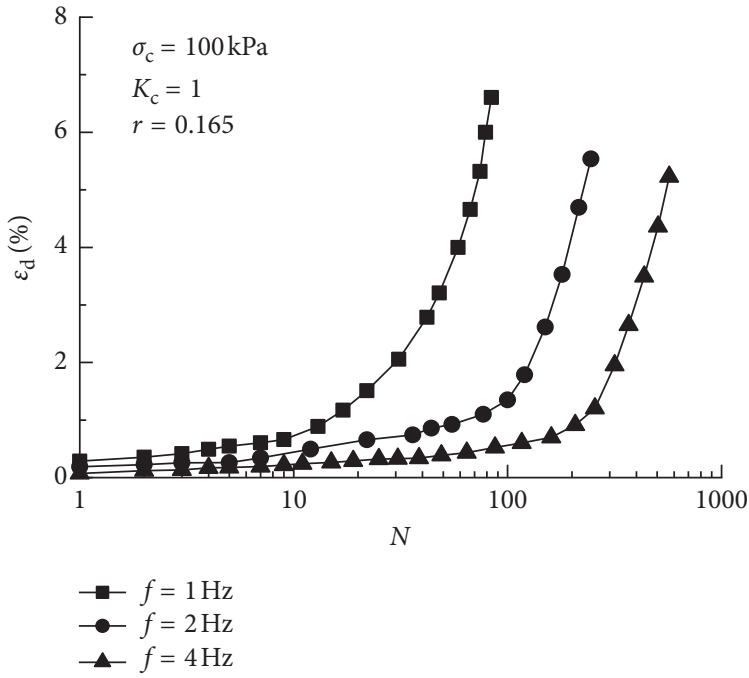

(b)

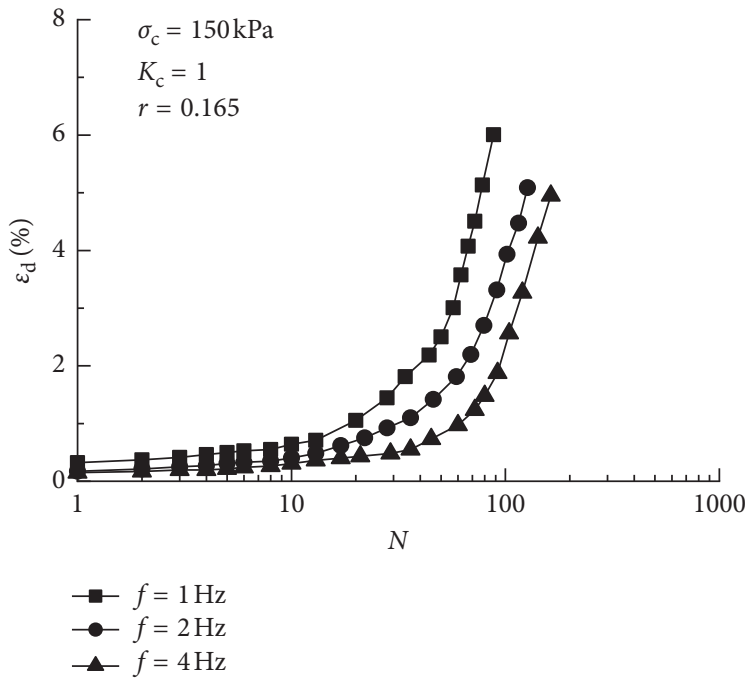

(c)

Figure 9: Relationship curves between $\varepsilon_{\mathrm{d}}$ and $N$ under different vibration frequencies. (a) $\sigma_{\mathrm{c}}=50 \mathrm{kPa}$. (b) $\sigma_{\mathrm{c}}=100 \mathrm{kPa}$. (c) $\sigma_{\mathrm{c}}=150 \mathrm{kPa}$.

the vibration frequency, the longer the vibration time. The pore water pressure in saturated clay has sufficient time to rise; thus, the effective stress in soil decreases, thereby decreasing soil strength. However, when the vibration frequency is large, the pore water pressure in soil will not rise quickly due to the hysteresis effect, and the strain will develop slowly. Deformation and failure will occur only if the number of vibrations is increased.

\subsection{Influence of Initial Shear Stress on the Dynamic Strength} Curve of Saturated Clay. Figure 10 shows the dynamic strength curves of saturated clay under different consolidation ratios. The initial shear stress has a significant effect on the dynamic strength of saturated clay. Under the same dynamic stress, the higher the initial shear stress level, the fewer the number of cycles required for the soil to reach the strain failure criterion, and the lower the dynamic strength of the soil. Under the same vibration frequency, the higher the initial shear stress level, the smaller the dynamic stress required for the soil to reach the strain failure criterion. The main reason is that the increase in initial shear stress will destroy the cohesion between clay particles, thereby considerably increasing the dynamic strain of clay under cyclic loading. Consequently, the turning point of dynamic strain will appear ahead of time and sudden failure will occur, thereby reducing the number of cycles of sample to failure. A turning point transpires in the dynamic strength curve of saturated clay under different consolidation ratios. The lower the initial shear stress level, the gentler the dynamic strength curves after the turning point and the smaller the tangent slope of the curve.

3.6. Influence of Vibration Frequency on the Dynamic Strength Curve of Saturated Clay. Figure 11 shows the dynamic 


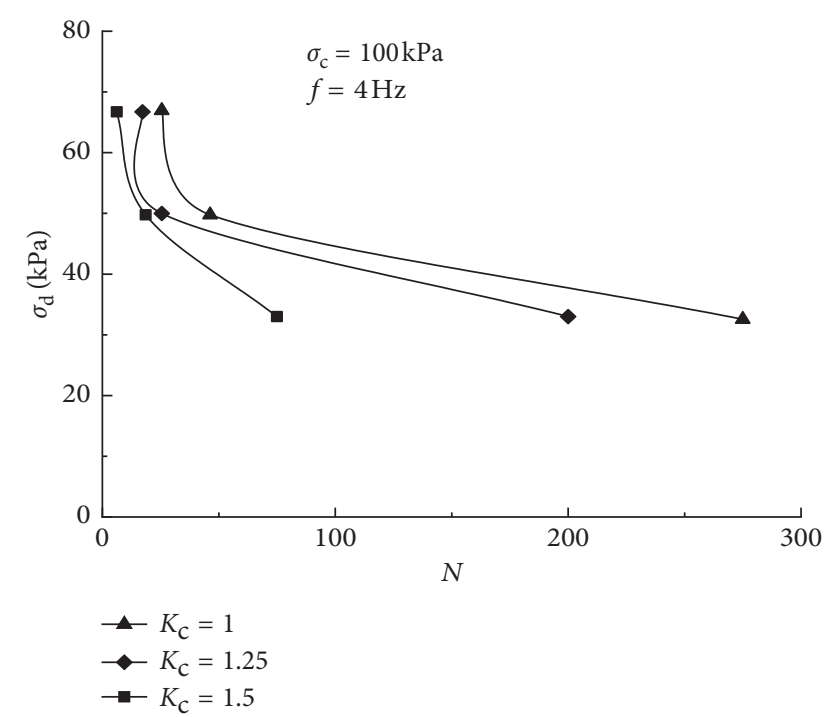

Figure 10: Dynamic strength curves of clay under different initial shear stresses.

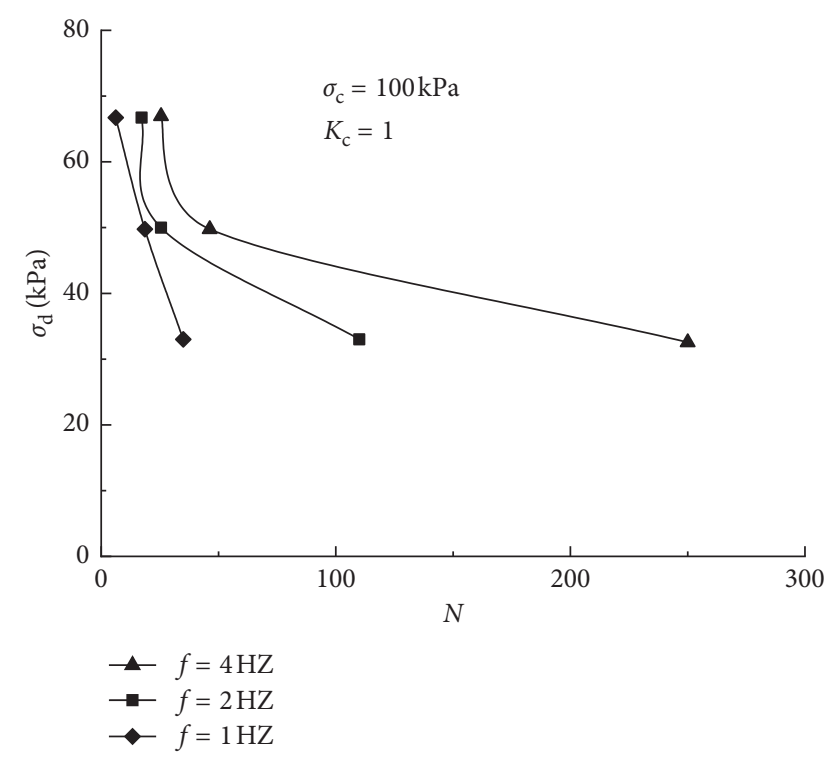

Figure 11: Dynamic strength curves of clay under different vibration frequencies.

strength curves of saturated clay under different vibration frequencies. The vibration frequency has a significant influence on the dynamic strength of soil. Under the same dynamic stress condition, the higher the frequency of vibration, the higher the number of vibrations required to cause soil failure, and the larger the dynamic strength of soil. Under the same number of cycles, the higher the vibration frequency, the higher the dynamic stress required to cause soil failure. The main reason is that when the vibration frequency is high, the dynamic pore pressure of saturated clay cannot rise and dissipate and the effective stress of soil and the shear strength will increase. A turning point occurs in the dynamic strength curve of saturated clay under different consolidation ratios. The higher the vibration frequency, the smoother the dynamic strength curves after the turning point and the smaller the tangent slope of the curve.

\section{Conclusions}

The deformation and strength characteristics of saturated clay in the Wenchuan earthquake area are investigated through a dynamic triaxial test system. The effects of initial shear stress, vibration frequency, and cyclic stress ratio on the deformation and strength of saturated clay are examined. Results show the following:

(1) A turning point occurs involving a sudden increase of deformation in the dynamic strain development of saturated clay. Before the turning point, the saturated clay shows a slow strain development rate. After the turning point, the saturated clay strain begins to increase sharply. The corresponding strain of the turning point is defined as the failure strain $\varepsilon_{\mathrm{tp}}$, and the corresponding number of cycles of the failure strain is the failure number of cycles $N_{f}$. Given the same confining pressure, the failure strains produced by different cyclic stress ratios have a linear relationship with the failure number of cycles.

(2) A critical cyclic stress ratio exists in saturated clay. When the cyclic stress ratio is less than the critical cyclic stress ratio, the dynamic strain of soil develops slowly in the initial stage of cyclic vibration, and a small recoverable elastic deformation is present. The dynamic strain does not begin to accumulate until a high number of vibrations have been achieved. When the cyclic stress ratio is larger than the critical dynamic stress, the dynamic strain of soil develops sufficiently and accumulates rapidly with the increase in the number of cycles until deformation and failure occur. The critical cyclic stress ratio is influenced by confining pressure and initial shear stress. The larger the confining pressure, the smaller the critical cyclic stress ratio. The larger the initial shear stress, the smaller the critical cyclic stress ratio.

(3) Initial shear stress and vibration frequency have significant effects on the dynamic strain development of saturated clay. The higher the initial shear stress or the lower the vibration frequency is, the more fully the dynamic strain develops and the fewer the number of cycles required to achieve the same dynamic strain.

(4) The initial shear stress and vibration frequency have significant effects on the dynamic strength of saturated clay. Under the same number of cycles, the larger the initial shear stress or the lower the vibration frequency is, the smaller the dynamic stress required to cause soil failure. The existence of initial shear stress reduces the dynamic strength of the soil.

(5) A turning point occurs in the dynamic strength curve of saturated clay. The lower the initial shear 
stress or the higher the vibration frequency, the smoother the dynamic strength curves after the turning point and the smaller the tangent slope of the curve.

\section{Data Availability}

The data used to support the findings of this study are included within the article.

\section{Conflicts of Interest}

The authors declare that there are no conflicts of interest regarding the publication of this paper.

\section{Acknowledgments}

The authors are grateful for the financial support from the National Natural Science Foundation of China (no. 51709145) and research project of the Ministry of Housing and Urban-Rural Development (no. 2019-K-131).

\section{References}

[1] K. Pan and Z. X. Yang, "Effects of initial static shear on cyclic resistance and pore pressure generation of saturated sand," Acta Geotechnica, vol. 13, no. 2, pp. 473-487, 2018.

[2] Z. X. Yang and K. Pan, "Flow deformation and cyclic resistance of saturated loose sand considering initial static shear effect," Soil Dynamics and Earthquake Engineering, vol. 92, pp. 68-78, 2017.

[3] A. Lashkari, A. Karimi, K. Fakharian, and F. KavianiHamedani, "Prediction of undrained behavior of isotropically and anisotropically consolidated Firoozkuh sand: instability and flow liquefaction," International Journal of Geomechanics, vol. 17, no. 10, Article ID 04017083, 2017.

[4] K. L. Lee, "Cyclic strength of a sensitive clay of eastern Canada," Canadian Geotechnical Journal, vol. 16, no. 1, pp. 163-176, 1979.

[5] K. Yasuhara, T. Yamanouchi, and K. Hirao, "Cyclic strength and deformation of normally consolidated clay," Soils and Foundations, vol. 22, no. 3, pp. 77-91, 1982.

[6] M. Hyodo, K. Yasuhara, and K. Hirao, "Prediction of clay behaviour in undrained and partially drained cyclic triaxial tests," Soils and Foundations, vol. 32, no. 4, pp. 117-127, 1992.

[7] A. S. Muhanna, A Testing Procedure and a Model for Resilient Modulus and Accumulated Plastic Strain of Cohesive Subgrade Soils, North Carolina State University, Raleigh, NC, USA, 1994.

[8] H. G. Larew and G. A. Leonards, "Repeated load strength criterion," in Proceedings of the Highway Research Board, pp. 529-556, Washington, DC, USA, January 1962.

[9] D. A. Sangrey, G. Castro, and S. J. Poulos, "Cyclic loading of sands, silts and clays," in Proceedings of the Conference on Earthquake Engineering and Soil Dynamics, pp. 836-851, Pasadena, CA, USA, June 1978.

[10] T. Matsui, H. Ohara, and T. Ito, "Cyclic stress strain history and shear characteristic of clays," Journal of Geotechnical Engineering, vol. 106, no. 10, pp. 1101-1120, 1980.

[11] A. M. Ansal and A. Erken, "Undrained behavior of clay under cyclic shear stresses," Journal of Geotechnical Engineering, vol. 115, no. 7, pp. 968-983, 1989.
[12] J. H. Brewer, The Response of Cyclic Stress in a Normally Consolidated Saturated Clay, North Carolina State University, Raleigh, NC, USA, 1972.

[13] G. G. Moses, S. N. Rao, and P. N. Rao, "Undrained strength behaviour of a cemented marine clay under monotonic and cyclic loading," Ocean Engineering, vol. 30, no. 14, pp. 1765-1789, 2003.

[14] A. K. Lashine, Some Aspects of the Characteristics of Keuper Marl under Repeated Loading, University of Nottingham, Nottingham UK, 1971.

[15] S. F. Brown, A. K. F. Lashine, and A. F. L. Hyde, "Repeated load triaxial testing of a silty clay," Géotechnique, vol. 25, no. 1, pp. 95-114, 1975.

[16] G. B. Parr, Some Aspects of the Behavior of London Clay under Repeated Loading, University of Nottingham, Nottingham UK, 1972.

[17] C. L. Monismith, N. Ogawa, and C. R. Freeme, Permanent Deformation Characteristics of Subgrade Soils Due to Repeated Loading, Transportation Research Board, Washington DC, USA, 1975.

[18] K. Yasuhara, "Postcyclic undrained strength for cohesive soils," Journal of Geotechnical Engineering, vol. 120, no. 11, pp. 1961-1979, 1994.

[19] I. Ishibashi, M. Kawamura, and S. K. Bhatia, "Effect of initial shear on cyclic behavior of sand," Journal of Geotechnical Engineering, vol. 111, no. 12, pp. 1395-1410, 1985.

[20] A. M. Goulois, R. V. Whitman, and K. Hoeg, "Effects of sustained shear stresses on the cyclic degradation of clay," in Strength Testing of Marine Sediments, vol. 883, pp. 336-351, ASTM Special Technical Publication, West Conshohocken, PA, USA, 1985.

[21] G. Lefebvre and P. Pfendler, "Strain rate and preshear effects in cyclic resistance of soft clay," Journal of Geotechnical Engineering, vol. 122, no. 1, pp. 21-26, 1996.

[22] G. G. Moses and S. N. Rao, "Behavior of marine clay subjected to cyclic loading with sustained shear stress," Marine Georesources and Geotechnology, vol. 25, no. 2, pp. 81-96, 2007.

[23] L.-L. Li, H.-B. Dan, and L.-Z. Wang, "Undrained behavior of natural marine clay under cyclic loading," Ocean Engineering, vol. 38, no. 16, pp. 1792-1805, 2011.

[24] J. Wang, Y. Cai, and F. Yang, "Effects of initial shear stress on cyclic behavior of saturated soft clay," Marine Georesources \& Geotechnology, vol. 31, no. 1, pp. 86-106, 2013.

[25] L. Sun, Y.-Q. Cai, C. Gu, J. Wang, and L. Guo, "Cyclic deformation behaviour of natural $K_{0}$-consolidated soft clay under different stress paths," Journal of Central South University, vol. 22, no. 12, pp. 4828-4836, 2015. 